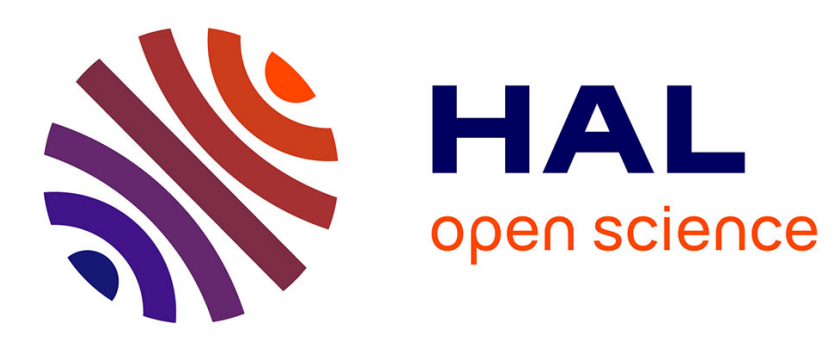

\title{
Mental Model Theory versus the Inference Rule Approach in relational reasoning
}

\author{
Jean-Baptiste van Der Henst
}

\section{To cite this version:}

Jean-Baptiste van Der Henst. Mental Model Theory versus the Inference Rule Approach in relational reasoning. Thinking \& Reasoning, 2002, 8, pp.193-205. hal-00000174

\section{HAL Id: hal-00000174 \\ https://hal.science/hal-00000174}

Submitted on 6 Feb 2003

HAL is a multi-disciplinary open access archive for the deposit and dissemination of scientific research documents, whether they are published or not. The documents may come from teaching and research institutions in France or abroad, or from public or private research centers.
L'archive ouverte pluridisciplinaire HAL, est destinée au dépôt et à la diffusion de documents scientifiques de niveau recherche, publiés ou non, émanant des établissements d'enseignement et de recherche français ou étrangers, des laboratoires publics ou privés. 
Mental Model Theory versus the Inference Rule Approach in relational reasoning:

Looking at the right place

Jean-Baptiste Van der Henst

K.U. Leuven

Correspondence:

Laboratory of Experimental Psychology, University of Leuven

102 Tiensestraat, 3000 Leuven, Belgium

Email: jvanderhenst@hotmail.com

Running Head: Models and rules in relational reasoning 
Abstract.

Researchers currently working on relational reasoning typically argue that mental model theory (MMT) is a better account than the inference rule approach (IRA). They predict and observe that determinate (or one-model) problems are easier than indeterminate (or twomodel) problems whereas according to them, IRA should lead to the opposite prediction. However, the predictions attributed to IRA are based on a mistaken argument. The IRA is generally presented in such a way that inference rules only deal with determinate relations and not with indeterminate ones. However, a) there is no reason to presuppose that rule-based procedure could not deal with indeterminate relations, and b) applying a rule-based procedure to indeterminate relations should result in greater difficulty. Hence, none of the recent articles devoted to relational reasoning currently presents a conclusive case for discarding IRA by using the well-known determinate vs. indeterminate problems comparison. 
Mental Model Theory versus the Inference Rule Approach in relational reasoning: Looking at the right place.

\section{Mental model theory and relational reasoning}

Human reasoning involves many inferences that depend on relations. Here is a typical example of a relational reasoning problem:

Problem 1.

1. A is to the right of $B$

2. $\mathrm{C}$ is to the left of $\mathrm{B}$

3. $\mathrm{D}$ is in front of $\mathrm{C}$

4. $\mathrm{E}$ is in front of $\mathrm{A}$

What is the relation between $\mathrm{D}$ and $\mathrm{E}$ ?

In 1989, Ruth Byrne and Philip Johnson-Laird published a well-known paper concerning relational reasoning and more specifically spatial reasoning. In this paper, the authors 1) apply Mental Model Theory (MMT) to spatial reasoning and 2) provide a test between MMT and its long-standing adversary, the Inference Rule Approach (IRA). A significant number of articles on relational reasoning have been published during the last decade and most, if not all, are in close continuity with Byrne and Johnson-Laird's study and likewise tend to reject the IRA. The purpose of the current paper is to present a criticism of the argument advanced for rejecting the IRA and to reassess the main result on which this argument relies. The paper is not intended as a criticism of MMT and its description of relational reasoning, but rather as claim that the dismissal of the IRA is based on a mistaken argument.

According to Byrne \& Johnson-Laird (1989), human reasoning relies on the construction and manipulation of mental models (Johnson-Laird, 1983; Johnson-Laird \& Byrne, 1991) and can be characterised as a three-step procedure. First, individuals construct a model of the state of affairs described in the premises, second they come up with a putative conclusion compatible with this model, and third they try to falsify this conclusion by constructing alternative models of the premises. MMT makes a very clear prediction in regard to problem difficulty: the larger the number of models compatible with a problem, the greater its difficulty.

For instance, Problem 1 above is compatible with one model:

$\begin{array}{lll}\text { C } & \text { B } & \text { A } \\ \text { D } & & \text { E }\end{array}$


From this model, the reasoner can draw the initial conclusion " $D$ is to the left of E". No other model is compatible with the premises. This problem is therefore labelled a "one-model" problem.

Consider now the "multiple-model" Problem 2 whose first premise is irrelevant: Problem 2:

1. B is to the right of $\mathrm{A}$

2. $\mathrm{C}$ is to the left of $\mathrm{B}$

3. $\mathrm{D}$ is in front of $\mathrm{C}$

4. $\mathrm{E}$ is in front of $\mathrm{B}$

What is the relation between $\mathrm{D}$ and $\mathrm{E}$ ?

For this problem, a first model is compatible with the premises:

C A B

D E

and supports the conclusion " $\mathrm{D}$ is to the left of E". In contrast with Problem 1, the search for alternative models may yield a second model consistent with the premises:

A $\quad$ C B

D E

However, the indeterminacy between the $\mathrm{A}$ and $\mathrm{C}$ does not matter for discovering the answer and both models support the same conclusion " $\mathrm{D}$ is to the left of E".

According to MMT, Problem 2 should be more difficult than Problem 1 because it is harder to deal with two models than with one model. In a series of experiments, Byrne \& Johnson-Laird (1989) exhibit clear-cut results that confirm this prediction. In their second experiment, $70 \%$ of the conclusions were correct for problems of type 1 (one-model problems) and $46 \%$ for problems of type 2 (two-model problems).

\section{Distinguishing between the Mental Model Theory and the Inference Rule Approach.}

1) The argument advocated by MMT's proponents.

The impact of Byrne \& Johnson-Laird's study does not only derive from their description of spatial reasoning in terms of mental models. It also rests on the fact that the obtained results are claimed to challenge the IRA. According to such approaches (Rips, 1994; Braine \& O'Brien, 1998), individuals are equipped with a set of mental inference rules and apply these rules to the logical form of the premises in order to derive conclusions. The difficulty of a problem depends on two factors: 1) the number of rules used to reach the 
conclusion: The larger the number of rules used, the greater the difficulty. 2) The difficulty weight associated to each rule.

The IRA is generally advocated for propositional reasoning, and the debate between MMT and IRA is mainly focused on this type of reasoning (Johnson-Laird, Byrne \& Schaeken, 1992; 1994; O’Brien, Braine \& Yang, 1994; Bonatti, 1994a, 1994b; Noveck \& Politzer, 1998). In the field of spatial reasoning, there are hardly any psychologists who currently defend an approach based on inference rules. However, the proponents of MMT claim that MMT and IRA make contrasting predictions concerning performance on spatial problems of the type used by Byrne \& Johnson-Laird (1989). In particular, they argue that the IRA, predicts that problems of type 1 would be more difficult than problems of type 2 , because they require an additional inferential step, whereas MMT makes the reverse prediction.

Indeed, in Problem 2 the relation between $\mathrm{C}$ and $\mathrm{B}$, to which $\mathrm{D}$ and $\mathrm{E}$ are directly related, is given by the second premise. In contrast, for Problem 1 there is no premise that asserts the relation between $\mathrm{A}$ and $\mathrm{C}$ to which $\mathrm{D}$ and $\mathrm{E}$ are related. Reasoners must first infer the relation between $\mathrm{A}$ and $\mathrm{C}$ - by a transitivity rule - in order to infer the relation between $\mathrm{D}$ and E, which makes the derivation longer than for Problem 2. In sum, they argue that the number of models for Problems 1 and 2 is not proportional to the number of formal steps carried out in order to reach the conclusion. Hence, the comparison between performance on Problems 1 and 2 looks crucial because it appears to provide a straightforward test between the two approaches. The empirical data seem to corroborate MMT and to refute IRA since Problem 2 is actually harder than Problem 1.

This result 1) is often mentioned (Byrne \& Johnson-Laird, 1992; Johnson-Laird \& Byrne, 1991; Evans, Newstead \& Byrne, 1993, Johnson-Laird, 1996; 1999; 2001; Vandierendonck, De Vooght, Desimpelaere \& Dierckx, 2000) and 2) has been often replicated in several sub-domains of relational reasoning, i.e. for spatial reasoning (Boudreau \& Pigeau, 2001; Carreiras \& Santamaria, 1997; Roberts, 2000, Vandierendonck \& De Vooght, 1996; 1998), temporal reasoning (Schaeken, Johnson-Laird \& d'Ydewalle, 1996a; 1996b; Schaeken, Girotto \& Johnson-Laird, 1998; Schaeken \& Johnson-Laird, 2000; Vandierendonck \& De Vooght, 1996; 1998), and abstract relational reasoning (Carreiras \& Santamaria, 1997). In all cases, this result is viewed as providing clear support for MMT and a clear refutation of the IRA. 


\section{2) Criticism}

The issue I wish to raise has to do with the argument that is developed against the IRA and with the interpretation of this "crucial" result. In Problem 2, the first premise generates, in the context of the other premises, an indeterminacy regarding the relation between $\mathrm{A}$ and $\mathrm{C}: \mathrm{A}$ can be on the right of $\mathrm{C}$, or on the left of C. According to the proponents of MMT, this indeterminacy causes the construction of two models. Moreover, they argue that inference rule theorists should adopt the following analysis: Since the first premise is irrelevant and the indeterminacy it conveys (in combination with Premise 2) does not matter for answering the question, participants need not take this premise into account to infer the conclusion.

Consequently, indeterminacy should not influence the reasoning procedure if people use rules. To illustrate, Byrne and Johnson-Laird (1989) give the following description of the rule application process for problems with an irrelevant premise like Problem 2:

"The first premise in the problem is irrelevant, and the inference rules must be used to derive relations between $\mathrm{D}, \mathrm{C}$ and $\mathrm{B}$, and then those relations between $\mathrm{D}, \mathrm{E}$, and $\mathrm{B}$ before there is sufficient information to use a rule to infer the relation between D and E" (p. 567).

This is indeed a description of how inference rules should be used to infer a conclusion as efficiently as possible. However, a description of how inferences rules should be used is not necessarily a description of how inferences rules are actually applied. Finding a logical proof of a conclusion does not mean that people will build such a proof when they reason. This description ignores the indeterminacy and thereby forecloses the possibility that inferences are applied to premises which support this indeterminacy. In sum, the opponents of the IRA claim that if what individuals do is construct mental models, the indeterminacy should influence the inferential process, but if what they do is apply inference rules, such an indeterminacy should have no effect at all. Let us note that the key point here is not the irrelevance of one the premises per se but the indeterminacy conveyed by such a premise. Even if all premises are relevant and still introduce an indeterminacy (see for instance Schaeken, et al., 1998), the indeterminacy is seen by the proponents of MMT as having no influence on a rule-based reasoning process. Hence, it is not the presence of an irrelevant premise that is the main "difficulty factor", as suggested by Rips (1994, p. 414-415) but the presence of indeterminacy. Schaeken et al. (1998) showed that even when all the premises were relevant, indeterminate problems were harder than indeterminate ones (Note 1). 
The difficulty of the argument proposed against the IRA is that there is no reason to disbar the IRA from taking into account the indeterminacy conveyed by the premises. The argument unduly presupposes that if the reasoner were to use formal inference rules he/she would know what information is necessary for solving the problem (i.e. the determinate relations) and what information is not (i.e. the indeterminate relation). Obviously, ignoring or taking into account some piece of information does not depend on the inferential device (rules or models) used but depends on heuristic and strategic aspects of reasoning (see Wood, 1969; Quinton \& Fellows, 1975). The comparison between problems 1 and 2 does not really provide a test between theories hypothesising two concurrent inferential mechanisms, but more modestly provides a test between a hypothesis $I$ assuming that participants take into account the indeterminacy since they do not know whether or not it is necessary for solving the problem, and a hypothesis $D I$ assuming that participants disregard indeterminacy. The error in the argument consists in expanding the IRA with one hypothesis DI and in expanding MMT with another hypothesis $I$. The comparison takes the following form:

$\mathrm{IRA}+$ DI versus $\mathrm{MMT}+I$.

If we now make the error in the opposite direction, then we will get a comparison favourable, this time, to the IRA:

IRA + I versus MMT $+D I$.

We can make this new comparison more explicit: 1) On the one hand, one could envisage a rule approach that takes into account indeterminacy. For instance, the following two rules, whose application gives an indeterminate conclusion, could be used in Problem 2:

1. Left $(y, x) \& \operatorname{Left}(z, x) \rightarrow \operatorname{Left}(y, z) \operatorname{OR} \operatorname{Left}(z, y)$

2. [Left (y, z) OR Left $(\mathrm{z}, \mathrm{y})] \&$ Front $(\mathrm{w}, \mathrm{z}) \rightarrow \operatorname{Left}(\mathrm{y}, \mathrm{w})$ OR Left $(\mathrm{w}, \mathrm{y})$

and could be added to the following set of relational rules (note 2):

3. Left (x, y) \& Front (z, x) $\rightarrow \operatorname{Left}(\mathrm{z}, \mathrm{y})$

4. Left $(\mathrm{x}, \mathrm{y}) \&$ Front $(\mathrm{z}, \mathrm{y}) \rightarrow \operatorname{Left}(\mathrm{x}, \mathrm{z})$

5. Left $(\mathrm{x}, \mathrm{y}) \& \operatorname{Left}(\mathrm{y}, \mathrm{z}) \rightarrow \operatorname{Left}(\mathrm{x}, \mathrm{z})$

6. Left (x, y) $\leftrightarrow$ Right (y, x)

One can then apply these rules to Problems 1 and 2. Given that for these two problems, reasoners cannot know in advance what relations are important for answering the question, they should consider that none of non-explicit relations should be overlooked. Hence, their strategy should consist in trying to discover all relations existing between all pairs of items which are not explicitly given in the premises. Linguistically propositionally

For Problem 1, the following steps would be pursued: 
$\mathrm{C} 1$ : ' $\mathrm{B}$ is to the left of $\mathrm{A}$ ' (Rule 6 to premise 1)

$\mathrm{C} 2$ : ' $\mathrm{C}$ is to the left of $\mathrm{A}$ ' (Rule 5 to premise 2 and $\mathrm{C} 1$ )

$\mathrm{C} 3$ : ' $\mathrm{D}$ is to the left of A' (Rule 3 to $\mathrm{C} 2$ and premise 3 )

C4: 'C is to the left of E' (Rule 4 to $\mathrm{C} 2$ and premise 4)

C5: 'D is to the left of B' (Rule 3 to premises 2 and 3)

C6: 'B is to the left of E' (Rule 4 to $\mathrm{C} 1$ and premise 4)

C7: 'D is to the left of E' (Rule 4 to $\mathrm{C} 3$ and premise 4 or Rule 5 to $\mathrm{C} 5$ and C6)

For Problem 2, the following steps would be pursued:

$\mathrm{C} 1$ : 'A is to the left of B' (Rule 6 to premise 1)

C2: 'A is to the left of C OR C is to the left of A' (Rule 1 to $\mathrm{C} 1$ and premise 2)

C3: 'A is to the left of D OR D is to the left of A' (Rule 2 to C2 and premise 3)

C4: 'A is to the left of E' (Rule 4 to $\mathrm{C} 1$ and premise 4)

C5: 'D is to the left of B' (Rule 3 to premises 2 and 3)

C6: ' $\mathrm{C}$ is to the left of E' (Rule 4 to premises 2 and 4)

C7: 'D is to the left of E' (Rule 4 to C5 and premise 4)

Hence, both problems give rise to the same number of inferential steps. However, in Problem 2, there is more information to store than in Problem 1 since two of the six non-explicit relations (i.e. $\mathrm{C} 2$ to $\mathrm{C} 7$ ) have a disjunctive form (i.e. $\mathrm{C} 2$ and $\mathrm{C} 3$ ) and contain thus two atomic propositions instead of one (it is a common observation that disjunctions are harder to manipulate than categorical assertions). For Problem 2, C2 and C3 represent twice more to store than in Problem 1, which makes Problem 2 more difficult than Problem 1. As for MMT, the greater difficulty of indeterminate problems from the perspective of IRA can be explained by the greater amount of relations to store. The only difference is that for MMT, relations are analogically represented whereas for IRA they are propositionally represented. Furthermore, one could also argue that rules 1 and 2 should be considered as more complex, and thus harder to apply, since they involve more atomic propositions than rules used for determinate problems (Rules 3 to 7). This is in line with recent claims of mental logicians who argue that a given inference rule has is own difficulty-weight and can be more or less difficult than another one (Yang, O’Brien and Braine, 1998; see also, Rips, 1994). Yet, an alternative view is to consider that there is no specific rule dealing with indeterminacy. But then, when the reasoner is trying to establish, say the A-C relation in Problem 2, he/she may apply a rule to premises containing items $\mathrm{A}$ and $\mathrm{C}$ but this will lead to an impasse; he/she can then reiterate with another rule and so on. After a while, he/she can then realise that the A-C relation cannot 
be known. These additional unsuccessful reasoning steps should lead to greater difficulty than when all relations can be established as it is for determinate problems (Note 3).

2) On the other hand one can conceive a model-based approach that constructs only necessary models and does not deal with indeterminacy when it is not necessary. Problem 2 is then a one-model problem:

C B

D E

and should be at least as easy as Problem 1. This time the better performance on Problem 1 in comparison to Problem 2 can be seen as corroborating IRA and refuting MMT. But again, this argument and the use of that result would, this time, be unfair to MMT. A more appropriate comparison would take the following form:

IRA + I versus MMT + I.

However, problems 1 and 2 do not provide a test for that comparison, because both approaches predict that Problem 2 would be harder than Problem 1.

\section{Conclusion}

In conclusion, tests between MMT and the IRA in the most recent publications on relational reasoning, which rely on a comparison between Problems 1 and 2, rest on a mistaken argument. The indeterminacy which occurs in Problem 2, is not pertinent to drawing contrasts between the two approaches. The superiority of MMT over IRA was attributed to the MMT's ability to explain how indeterminacy increases difficulty. But the difficulty caused by the indeterminacy can be accounted for by both approaches. According to MMT, indeterminacy involves the construction of several models. According to a rule approach, it involves more propositional information to store and manipulate in memory. Though empirical data in relational reasoning are neatly described by MMT, they do not exclude a description based on inference rules.

The fact that most psychologists reject the IRA on the basis of an inappropriate argument does not mean that their findings are not meaningful. First, they have obtained results that are compatible with MMT. Second, they have shown that the increase in difficulty with the number of models is not restricted to spatial relations but applies more generally, for instance to temporal and abstract relations. Third, some studies have contributed to a better understanding of the model construction process. For instance, Schaeken, et al. (1996a), and Carreiras \& Santamaria (1997), obtained results on reaction time in line with a parallel construction of models rather than the sequential construction originally hypothesised. In 
sum, these studies show that MMT can accommodate an impressive range of findings, but do not provide decisive evidence against the IRA.

Though psychologists should refrain from deciding between MMT and IRA on the basis of differences in performance on problems of type 1 and 2, this does not imply that they should altogether abandon attempts to distinguish the two approaches. Another way to compare the two approaches might consist in considering other type of data than the difference in error rate between problems supposed to be hard for MMT and easy for IRA and problems supposed to be easy for MMT and hard for IRA. For instance, Vandierendonck and De Vooght (1997) have shown that the visuo-spatial sketch pad is largely involved in reasoning with spatial and temporal relations. Their results reveal that premises' reading time increases when visuo-spatial processing is impaired by a secondary task. However, when a secondary task interferes with linguistic-phonological processes, premises' reading time does not increase. This suggests that the visuo -spatial sketch pad is necessary to solve relational problems and that premises are coded in a visuo-spatial format (see also Klauer, Stegmaier \& Meiser, 1997). In the same vein, Goel and Dolan (2001) conducted a neuroimaging study with spatial and nonspatial relational reasoning and reported results indicating that neural structures known to be involved in the processing of visuo-spatial information were activated in resolution of such problems. These new set of data seem to provide a more promising support for MMT than the traditional comparison between Problems 1 and 2.

However, a purist could always argue that the most elegant comparison should involve predictions relying on a clear description of the computational steps of each inferential procedure (search for alternatives vs. rule application) rather than on the mere nature of cognitive processes (analogical vs. propositional). Consequently, relational problems remain to be found for which the two approaches unambiguously generate contrasting predictions in terms of performance results. But this might be problematical since an increase of difficulty from the model perspective involves also an increase of difficulty from the rule perspective. 


\section{Acknowledgements}

I am grateful to Ira Noveck, Jeremy Pacht, Guy Politzer, Walter Schaeken, and Walter Schroyens, for their instructive comments on a previous version of the paper and to the members of the reasoning group in Leuven for their support: Wim DeNeys, Kristien Dieussaert, Leon Horsten, Nikki Verschueren, and Géry d'Ydewalle. I am also grateful to Richard Griggs, Maxwell Roberts and two anonymous reviewers for their critical reading of earlier drafts of the article.

\section{References}

Bonatti, L. (1994a). Propositional reasoning by models? Psychological Review, 101, 725-733.

Bonatti, L (1994b). Why should we abandon the mental logic hypothesis? Cognition,

Braine, M.D.S., \& O'Brien, D.P. (1998). Mental Logic. Mahwah, NJ: Lawrence Erlbaum Associates.

Boudreau, G. \& Pigeau, R. (2001). The mental representation and processes of spatial deductive reasoning with diagrams and sentences. International Journal of Psychology, 36, $42-52$.

Byrne, R.M.J. \& Johnson-Laird, P.N. (1989). Spatial reasoning. Journal of Memory and Language, 28, 564-575.

Byrne, R.M.J. \& Johnson-Laird, P.N. (1992). Models and deductive reasoning. In Gilhooly, Keane, M.T.G., Logie, R.H. \& Erdos, G. (Eds), Lines of Thinking. Reflections on the Psychology of Thought.

Carreiras, C. \& Santamaria, C. (1997). Reasoning about relations : spatial and nonspatial problems. Thinking and Reasoning, 3, 309-327.

Evans, J.St.B.T., Newstead, S.E., \& Byrne, R.M.J. (1993). Human reasoning. The Psychology of Deduction. Hove, UK: Lawrence Erlbaum Associates.

Goel, V. \& Dolan, R.J. (2001) Functional neuroanatomy of three-term relational reasoning. Neuropsychologia, 39, 901-909

Hagert, G. (1984). Modeling mental models: Experiments in cognitive modeling spatial reasoning. In T. O'Shea (Ed.), Advances in artificial intelligence, pp. 389-398. Amsterdam: North-Holland.

Johnson-Laird, P.N. (1983). Mental Models. Cambridge: Cambridge University Press. 
Johnson-Laird, P.N. (1996). Space to think. In Bloom, P., Peterson, M.A., Nadel, L. \& Garrett, M.F. (Eds), Language and space. Cambridge: The MIT Press

Johnson-Laird, P.N. (1999). Deductive reasoning. Annual Review of Psychology, 50, 109-135.

Johnson-Laird, P.N. (2001). Mental models and deductive reasoning. Trends in Cognitive Science, 5.

Johnson-Laird, P.N. \& Byrne, R.J.M. (1991). Deduction. Hove, U.K: Lawrence Erlbaum Associates.

Johnson-Laird, P.N., Byrne, R.J.M. \& Schaecken, W. (1992). Propositional reasoning by model. Psychological Review, 99, 418-439.

Johnson-Laird, P.N., Byrne, R.J.M. \& Schaecken, W. (1994). Why models rather than rules give a better account of propositional reasoning: a reply to Bonatti and to O'Brien, Braine and Yang. Psychological Review, 101, 734-739.

Klauer, K.C., Stegmaier, R. \& Meiser, T. (1997) Working memory involvement in propositional and spatial reasoning. Thinking and Reasoning, 3, 9-47

Noveck, I \& Politzer, G. (1998). Leveling the playing field. In Braine, M.D.S. \& O’Brien, D.P. (Eds.). Mental Logic. Mahwah, NJ: Lawrence Erlbaum Associates.

O’Brien, D.P., Braine, M.D.S. \& Yang. Y. (1994). Propositional reasoning by models? Simple to refute in principle and in practice. Psychological Review, 101, 711-724.

Quinton, G. \& Fellows, B.J. (1975). 'Perceptual' strategies in the solving of three-term series problems. British Journal of Psychology, 66, 69-78.

Rips, L.J. (1994). The psychology of proof. Deductive reasoning in human thinking. Cambridge, Massachutsetts, MIT Press, Bradford

Roberts, M.J. (2000). Strategies in relational reasoning Thinking and Reasoning, 6, 126.

Schaecken, W., Girotto, V. \& Johnson-Laird, P.N. (1998). The effect of irrelevant premise on temporal and spatial reasoning. Kognitionswissenchaft, 7, 27-32.

Schaecken, W. Johnson-Laird, P.N. (2000). Strategies in temporal reasoning. Thinking and Reasoning, 6, 193-219.

Schaecken, W., Johnson-Laird, P.N. \& d'Ydewalle, G. (1996a). Mental models and temporal reasoning. Cognition, 60, 205-234.

Schaecken, W., Johnson-Laird, P.N. \& d'Ydewalle, G. (1996b). Tense, aspect and temporal reasoning. Thinking and Reasoning, 2, 309-327. 
Van der Henst, J.B. (1999). The mental model theory of spatial reasoning re-examined: The role of relevance in premise order. British Journal of Psychology, 90, 73-84.

Vandierendonck A, \& De Voogt G. (1996). Evidence for mental-model-based reasoning: comparison of reasoning with time and space concepts. Thinking and Reasoning 2, 249- 272.

Vandierendonck A, \& De Voogt G. (1997). Working memory constraints on linear reasoning with spatial and temporal contents. Quarterly Journal of Experimental Psychology, $50,803-820$.

Vandierendonck A, \& De Voogt G. (1998). Mental models and working memory in temporal and spatial reasoning. In De Keyser, V. Et al. (Ed.) Time and dynamic control of behaviour. (pp. 383-402).

Vandierendonck, A., De Vooght, G., Desimpelaere, C. \& Dierckx, V. (2000). Model construction and elaboration in spatial linear syllogisms. In Schaeken, W. \& al. (Ed). Deductive reasoning and strategies.

Wood, D.J., (1969). Approach to the study of human reasoning. Nature, 223, 102-103

Yang, Y. Braine, M.D.S. \& O'Brien D.P. (1998). Some empirical justification of the mental-predictate-logic model. In Braine, M.D.S. \& O’Brien, D.P. (Eds.). Mental Logic. Mahwah, NJ: Lawrence Erlbaum Associates. 


\section{Notes}

Note 1:

Although the presence of an indeterminacy unambiguously contributes to increase difficulty, the impact of irrelevant information is not so clear: Vandierendonck et al. (1996 p.257) found that one-model problems with an irrelevant premise were harder than one-model problems with no irrelevant premise and took more time to be solved (p. 260). But these results were not observed by Schaeken et al. (1996a) who did not found any difference between the two types of problems (p. 226; 228).

Note 2:

These rules consist of a simplification of the Hagert's rules (1984) presented by Byrne and Johnson-Laird (1989). For instance, Rule 3 is a logical consequence of rules 'a' and 'e' described in Byrne and Johnson-Laird (1989):

Rule 'a': Left (x, y) \& Front (z, x) $\rightarrow$ Left (front $(z, x), y)$.

Rule 'e': Left (front $(\mathrm{z}, \mathrm{x}), \mathrm{y})) \rightarrow \operatorname{Left}(\mathrm{z}, \mathrm{y}) \& \operatorname{Left}(\mathrm{x}, \mathrm{y}) \&$ Front $(\mathrm{z}, \mathrm{x})$.

Note 3:

An anonymous reviewer also suggested that instead of inferring all the non-explicit relations, which requires keeping track of all the premises, individuals might follow a more economical strategy by only inferring conclusions from the last processed information in working memory and the new incoming premise.

For Problem 1, the following steps would thus be pursued:

$\mathrm{C} 1$ : 'B is to the left of A' (Rule 6 to premise 1)

$\mathrm{C} 2$ : ' $\mathrm{C}$ is to the left of $\mathrm{A}$ ' (Rule 5 to premise 2 and $\mathrm{C} 1$ )

C3: ' $\mathrm{D}$ is to the left of $\mathrm{A}$ ' (Rule 3 to $\mathrm{C} 2$ and premise 3)

C4: 'D is to the left of E' (Rule 4 to $\mathrm{C} 3$ and premise 4)

Such a strategy would permit to answer the question asked in Problem 1. However, the strategy would be less successful for Problem 2. The following steps would be first be pursued:

$\mathrm{C} 1$ : 'A is to the left of B' (Rule 6 to premise 1)

$\mathrm{C} 2$ : ' $\mathrm{A}$ is to the left of $\mathrm{C}$ OR $\mathrm{C}$ is to the left of $\mathrm{A}$ ' (Rule 1 to $\mathrm{C} 1$ and premise 2)

C3: 'A is to the left of D OR D is to the left of A' (Rule 2 to $C 2$ and premise 3) 
However, at this point C3 cannot interact with premise 4. The reasoner may stop his/her reasoning here and would not find out the relation between $\mathrm{D}$ and $\mathrm{E}$. $\mathrm{He} / \mathrm{she}$ can also reiterate the premises and restart a proof from another premise, like premise 2:

$\mathrm{C} 4$ : ' $\mathrm{D}$ is to the left of B' (Rule 3 to premises 2 and 3 )

C5: 'D is to the left of E' (Rule 4 to C4 and premise 4).

In any case, Problem 2 would lead to more erroneous answers than Problem 1. 